\title{
Heterologous expression of glucose oxidase in the yeast Kluyveromyces marxianus
}

\author{
Saul N Rocha1', José Abrahão-Neto², María E Cerdán, María I González-Siso³, Andreas K Gombert ${ }^{\text {* }}$
}

\begin{abstract}
Background: In spite of its advantageous physiological properties for bioprocess applications, the use of the yeast Kluyveromyces marxianus as a host for heterologous protein production has been very limited, in constrast to its close relative Kluyveromyces lactis. In the present work, the model protein glucose oxidase (GOX) from Aspergillus niger was cloned into K. marxianus CBS 6556 and into K. lactis CBS 2359 using three different expression systems. We aimed at verifying how each expression system would affect protein expression, secretion/localization, posttranslational modification, and biochemical properties.

Results: The highest GOX expression levels (1552 units of secreted protein per gram dry cell weight) were achieved using an episomal system, in which the INU1 promoter and terminator were used to drive heterologous gene expression, together with the INU1 prepro sequence, which was employed to drive secretion of the enzyme. In all cases, GOX was mainly secreted, remaining either in the periplasmic space or in the culture supernatant. Whereas the use of genetic elements from Saccharomyces cerevisiae to drive heterologous protein expression led to higher expression levels in K. lactis than in K. marxianus, the use of INU1 genetic elements clearly led to the opposite result. The biochemical characterization of GOX confirmed the correct expression of the protein and showed that K. marxianus has a tendency to hyperglycosylate the protein, in a similar way as already observed for other yeasts, although this tendency seems to be smaller than the one of e.g. K. lactis and S. cerevisiae. Hyperglycosylation of GOX does not seem to affect its affinity for the substrate, nor its activity.
\end{abstract}

Conclusions: Taken together, our results indicate that $K$. marxianus is indeed a good host for the expression of heterologous proteins, not only for its physiological properties, but also because it correctly secretes and folds these proteins.

\section{Background}

Kluyveromyces marxianus is a close relative of $K$. lactis, a model Crabtree-negative yeast, which has been investigated quite extensively by the research community [1-3]. In contrast to the latter, $K$. marxianus has not been the target of systematic investigation efforts. Thus, there is no publicly available genome sequence, no commercial cloning system, and no strain adopted as a reference for basic research purposes for this species [4]. Nevertheless, it has been constantly pointed out as an attractive candidate microorganism for biotechnological applications, due to some of its physiological properties, such as thermotolerance, the capacity of catabolising a broader range of substrates than e.g. S. cerevisiae, a

\footnotetext{
* Correspondence: andreas.gombert@poli.usp.br

'Department of Chemical Engineering, Polytechnic School of Engineering, University of São Paulo, CP 61548, 05424-970 São Paulo-SP, Brazil
}

strong Crabtree-negative or respiratory metabolism, which leads to high biomass yields on sugar substrates, and high growth rates. In this latter aspect, it has even been labeled the fastest growing eukaryote on the planet $[1,5,6]$.

The lack of an organized research community behind the species $K$. marxianus causes difficulty in extracting objective information about basic aspects of this species. Several different strains have been reported in the literature, many of them not available in the most common international culture collections. On the other hand, the possibilities of exploring this yeast for industrial applications seem to be manyfold. Among them, the production of heterologous proteins is especially attractive, in view of the key physiological properties indicated above. Other yeasts have been more extensively explored for this purpose. Besides S. cerevisiae, the most common 
hosts for the expression of heterologous proteins are Pichia pastoris, Hansenula polymorpha, Yarrowia lipolytica, and also K. lactis [3,7-11]. For many of these species, research is quite advanced, with most of the current works focusing on aspects such as the humanization of the secretory pathway, also referred to as glycoengineering, essential for the production of therapeutic proteins, and the search for super-secreting phenotypes [12-14].

Overexpression of foreign genes in $K$. marxianus has been reported in a few articles. After the pioneering work of Bergkamp et al., who expressed alpha-galactosidase of the plant Cyamopsis tetragonoloba at $153 \mathrm{mg} / \mathrm{L}$ with $99 \%$ secretion efficiency (including both the periplasmic and the fully secreted fractions), it took some time before Ball et al. reported on the expression of heterologous beta-glucuronidase or overexpression of homologous beta-glucosidase at levels as high as $10 \mathrm{U} /$ $\mathrm{mg}$ protein for the latter enzyme (data obtained from graphs) [15,16]. Later, Almeida et al. expressed the glyceraldehyde-3-phosphate dehydrogenase gene of a flocculent $K$. marxianus strain in another non-flocculent strain of the same species, provoking flocculation in the latter [17]. Pecota et al. reported on the intracellular production of heterologous beta-glucuronidase in $K$. marxianus at ca. $30 \mathrm{U} / \mathrm{L}$ (data taken from graphs) [18]. Around the same time, Cai et al. reported on the secretory expression of human interferon alpha-2a at $60 \mathrm{mg} /$ $L$ in a strain of $K$. cicerisporus (a synonym of $K$. marxianus) [19]. Subsequently, Pecota et al. expressed lactate dehydrogenase from Bacillus megaterium in K. marxia$n u s$, which led to the extracellular production of $24 \mathrm{~g} / \mathrm{L}$ of lactic acid [20]. Hong et al. simultaneously expressed the thermostable endo-beta-1,4-glucanase, cellobiohydrolase, and beta-glucosidase genes, leading to a strain that can grow on cellobiose or carboxymethyl-celulose as sole C-sources [21]. This strain could not produce ethanol from the latter C-source, but presented high ethanol yield on cellobiose. More recently, Nonklang et al. reported on the expression of alpha-amylase from Aspergillus oryzae in K. marxianus, without providing quantitative data on the levels of heterologous protein obtained [22].

In terms of the glycosylation capacity of $K$. marxianus, there is very limited information available. Siekstele et al. overexpressed the endopolygalacturonase (EPG1) gene of $K$. marxianus in an EPG1 deletion strain of the same background [23]. In contrast to native EPG1 expression, overexpression of this gene led to an additional band on the protein gel, of higher molecular weight, suggesting that a more glycosylated form of the enzyme is secreted during overexpression, together with the native form. Schwan et al. reported on the native secretion of polygalacturonases in $K$. marxianus [24]. At least four isoenzymes were identified according to the molecular weight, which could be a result of different glycosylation patterns of the same enzyme, according to the authors. Rouwenhorst et al. verified polidispersity of inulinase bands, both when the supernatant and the cell wall (periplasmic) enzyme were analysed, during cultivations of $K$. marxianus CBS 6556 [25]. This observation was attributed to heterogeneity in the size of the polysaccharide chains attached to the inulinase polypeptide.

In this study, the enzyme glucose oxidase (EC 1.1.3.4), which catalyses the oxidation of glucose to gluconolactone and the subsequent reduction of oxygen to hydrogen peroxide was used as model of protein expression in $K$. marxianus. The enzyme contains one very tightly, but nonconvalently bound FAD cofactor per monomer and is a homodimer with molecular mass of 130-320 $\mathrm{kDa}$, depending on the extent of glycosylation. The native enzyme is glycosylated, with a carbohydrate mass percentage of 16-25\% [26]. The enzyme expressed in $S$. cerevisiae led to a highly glycosylated form, with a carbohydrate mass percentage approximating 60\% [27]. With the aim of evaluating the potential of $K$. marxianus as a host for heterologous protein production, not only in terms of protein levels, but also in terms of glycosylation, localization and thermokinetic properties of the heterologous protein, we cloned the gene for the model protein glucose oxidase from Aspergillus niger BT18 into K. marxianus CBS 6556 and into K. lactis CBS 2359, using different episomal and integrative constructs. This protein offers a great potential for comparison with other expression systems. As far as we are aware, this is the first report of a heterologous protein expressed in $K$. marxianus, for which the glycosylation pattern, localization, stability and kinetic properties were investigated. Three different genetic constructs were used to direct heterologous glucose oxidase expression, which was also followed in the reference yeast $K$. lactis, allowing for a direct comparison between the two organisms.

\section{Results and Discussion GOX expression levels}

In the present study, for all constructs (shown on Table 1 and Figure 1), it was possible to detect GOX activity, although in one particular construct (Km1), GOX activity was quite low (Table 2). In all cases, the great majority of the enzyme (> 80\%) was secreted from the cells (Table 3), either to the periplasmic space or to the supernatant. The use of $S$. cerevisiae elements for driving GOX expression led to higher heterologous GOX levels in $K$. lactis than in $K$. marxianus. This observation is in accordance with previously reported data by Bergkamp et al., who observed much higher expression of recombinant alpha-galactosidase in K. lactis CBS 2359 
Table 1 Heterologous GOX constructions.

\begin{tabular}{|c|c|c|c|c|c|c|}
\hline Construction & Host Organism & Plasmid name & Type & Promoter & Signal sequence & Terminator \\
\hline $\mathrm{Km} 1$ & K. marxianus & pSPGOX & Episomal & SCPGK & Kl k1 & SC PGK \\
\hline $\mathrm{Km} 2$ & K. marxianus & pSPINGOX & Episomal & Km INU1 & Km INU1 & Km INU1 \\
\hline Km3 & K. marxianus & pINGOXi & Integrative & Km INU1 & Km INU1 & Km INU1 \\
\hline $\mathrm{Kl1}$ & K. lactis & pSPGOX & Episomal & SC PGK & Kl k1 & SC PGK \\
\hline $\mathrm{KI} 2$ & K. lactis & pSPINGOX & Episomal & Km INU1 & Km INU1 & Km INU1 \\
\hline $\mathrm{KI} 3$ & K. lactis & pINGOXi & Integrative & Km INU1 & Km INU1 & Km INU1 \\
\hline
\end{tabular}

List of the six constructions obtained in this work and their details.

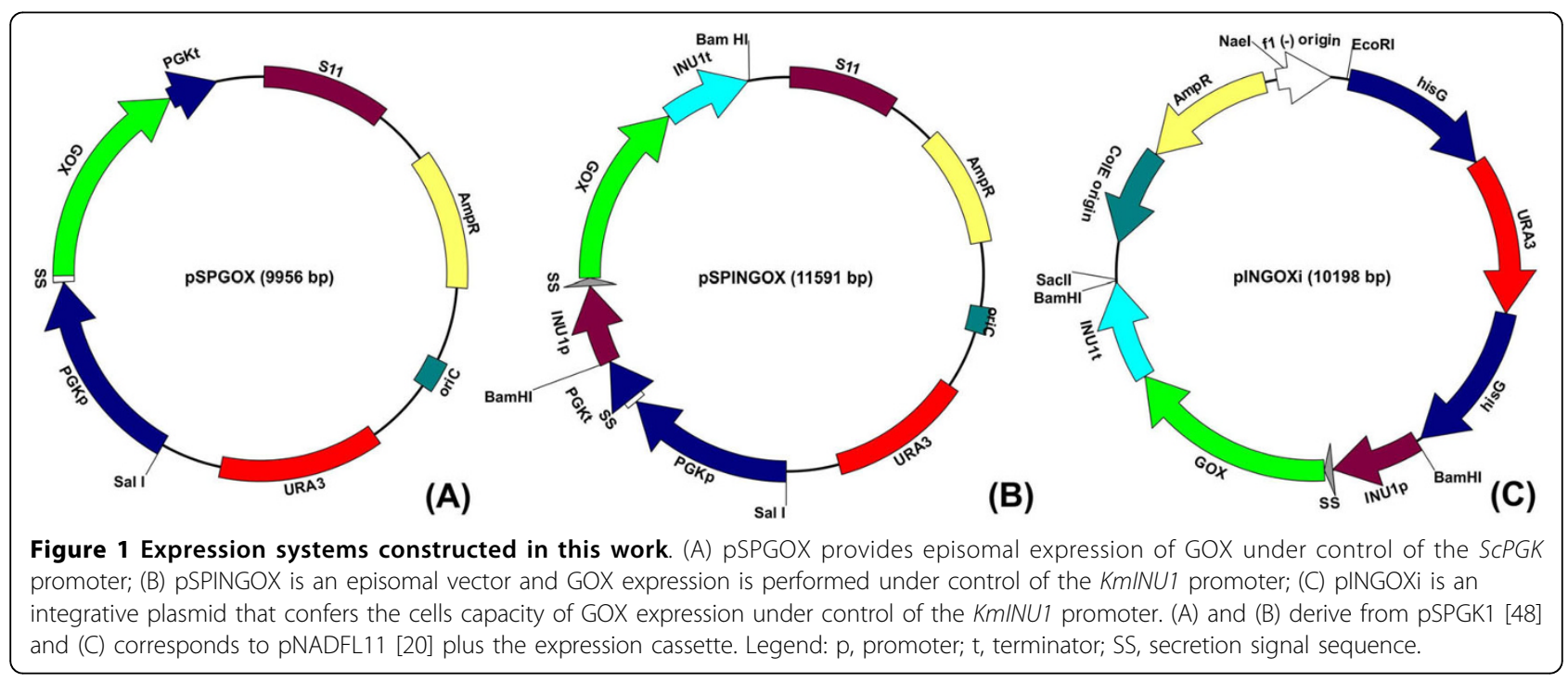

Table 2 GOX enzymatic activities.

\begin{tabular}{|c|c|c|c|c|c|c|c|c|}
\hline \multirow[t]{3}{*}{ Construction $^{(\mathrm{a})}$} & \multirow{3}{*}{$\begin{array}{c}\begin{array}{c}\text { Final } \\
\text { Biomass }^{\mathbf{b}}\end{array} \\
(\mathrm{gDW} / \mathrm{L})\end{array}$} & \multicolumn{7}{|c|}{ GOX activity $^{(\mathrm{c})}$} \\
\hline & & \multicolumn{2}{|c|}{ Supernatant } & \multicolumn{2}{|c|}{ Cell wall } & \multicolumn{2}{|c|}{ Cell-bound } & \multirow{2}{*}{$\begin{array}{c}\text { Total } \\
\text { U/gDW }\end{array}$} \\
\hline & & U/mgProt & U/gDW & U/mgProt & U/gDW & U/mg Prot & U/gDW & \\
\hline $\mathrm{Km} 1$ & $7.4 \pm 0.3$ & $0.3 \pm 0.1$ & $0.5 \pm 0.1$ & $2.4 \pm 0.1$ & $1.9 \pm 0.1$ & $0.03 \pm 0.02$ & $4.0 \pm 1.4$ & $7.4 \pm 2.5$ \\
\hline $\mathrm{Km} 2$ & $12.1 \pm 0.2$ & $251 \pm 72$ & $407 \pm 16$ & $180 \pm 24$ & $1145 \pm 35$ & $1.3 \pm 0.2$ & $171 \pm 44$ & $1722 \pm 62$ \\
\hline $\mathrm{Km} 3$ & $12.0 \pm 0.1$ & $171 \pm 44$ & $255 \pm 1$ & $187 \pm 8$ & $850 \pm 70$ & $2.4 \pm 0.3$ & $291 \pm 27$ & $1395 \pm 42$ \\
\hline $\mathrm{Kl} 1$ & $9.9 \pm 0.2$ & $40 \pm 3$ & $161 \pm 17$ & $16 \pm 1$ & $13 \pm 1$ & $0.3 \pm 0.1$ & $31 \pm 2$ & $205 \pm 16$ \\
\hline $\mathrm{KI} 2$ & $11.2 \pm 0.0$ & $32 \pm 1$ & $94 \pm 6$ & $64 \pm 5$ & $49 \pm 8$ & $0.1 \pm 0.0$ & $16 \pm 3$ & $158 \pm 17$ \\
\hline $\mathrm{Kl} 3$ & $9.6 \pm 0.2$ & $29 \pm 1$ & $94 \pm 12$ & $76 \pm 4$ & $64 \pm 0$ & $0.1 \pm 0.0$ & $13 \pm 1$ & $170 \pm 11$ \\
\hline
\end{tabular}

Heterologous GOX production in the supernatant, cell wall and cell-bound fractions of different $K$. marxianus and $K$. lactis strains.

(a) see Materials and Methods section, Table 1 and Figure 1 for a description of the genetic constructions.

(b) see Materials and Methods section, for a description of the cultivation conditions.

(c) subcellular distribution according to Rouwenhorst et al. [50]

(90 mg/L), when compared to K. marxianus CBS 6556 (2 mg/L), when using either GLC7 or PGK promoterdriven expression (both promoters from $S$. cerevisiae) $[15,28]$. Since the level of GOX expression in the $\mathrm{Km} 1$ construct was so low, it was not possible to verify whether the secretion signal $\mathrm{k} 1$ of $K$. lactis works well for secretion in $K$. marxianus.

A strong increase in the levels of heterologous GOX was obtained in $K$. marxianus when the homologous
INU1 promoter and secretion signal were employed to drive heterologous gene expression, when compared to the use of a $S$. cerevisiae promoter with a $K$. lactis secretion signal. This also agrees with the results reported by Bergkamp et al., who obtained $153 \mathrm{mg} / \mathrm{L}$ of heterologous alpha-galactosidase (including both the periplasmic and the supernatant fractions) in $K$. marxianus, using the INU1 promoter and secretion signal, compared to 2 $\mathrm{mg} / \mathrm{L}$ when the $S$. cerevisiae elements mentioned above 
Table 3 GOX distribution.

\begin{tabular}{lccc}
\hline Construction $^{(\mathbf{a})}$ & $\begin{array}{c}\text { GOX activity per } \\
\text { g DW in each fraction relative to } \\
\text { the total }\end{array}$ \\
\hline & Supernatant $\mathbf{c}$ \\
\hline $\mathrm{Km} 1$ & Cell wall & Cell-bound \\
$\mathrm{Km} 2$ & $9 \% \pm 3 \%$ & $31 \% \pm 8 \%$ & $62 \% \pm 11 \%$ \\
$\mathrm{Km} 3$ & $23 \% \pm 2 \%$ & $67 \% \pm 1 \%$ & $10 \% \pm 3 \%$ \\
$\mathrm{Kl} 1$ & $19 \% \pm 1 \%$ & $61 \% \pm 3 \%$ & $21 \% \pm 2 \%$ \\
$\mathrm{KI} 2$ & $79 \% \pm 2 \%$ & $6 \% \pm 0 \%$ & $16 \% \pm 2 \%$ \\
$\mathrm{Kl} 3$ & $60 \% \pm 2 \%$ & $31 \% \pm 2 \%$ & $10 \% \pm 0 \%$ \\
\hline
\end{tabular}

Subcellular distribution of heterologous GOX in different $K$. marxianus and $K$. lactis strains.

(a) see Materials and Methods section, Table 1 and Figure 1 for a description of the genetic constructions.

(b) see Materials and Methods section, for a description of the cultivation conditions.

(c) subcellular distribution according to Rouwenhorst et al. [50]

were employed [15]. These authors estimated the plasmid copy number per cell to be 25 in their studies. However, this much higher expression level of alphagalactosidase obtained using the INU1-derived constructions cannot be explained exclusively by the increased plasmid copy number (the expression level increased 75 times), and is probably also caused by an increased plasmid stability and promoter strength in the host. Interestingly, the amount of heterologous protein obtained in the present work is very similar to the one obtained in the referred work. If we assume a conversion factor of 80-172 U/mg protein for glucose oxidase, we can estimate the extracellular production of glucose oxidase in the $\mathrm{Km} 2$ construct to be between 90 and $194 \mathrm{mg} / \mathrm{L}$ [29]. Bergkamp et al. used a conversion factor of $100 \mathrm{U} / \mathrm{mg}$ to calculate the $153 \mathrm{mg} / \mathrm{L}$ of heterologous protein obtained in their work $[15,28]$.

The enhancing effect of the INU1 promoter and secretion signal on GOX expression was exclusive to $K$. marxianus, since in the $K$. lactis constructs using this system ( $\mathrm{Kl} 2$ and $\mathrm{Kl} 3$ ), the levels of total GOX produced were even slightly lower than the levels attained with the $S$. cerevisiae promoter and k1 secretion signal (K11) (Table 2). In particular, the secretion efficiency of heterologous GOX using the KmINU1 pre-pro sequence was much lower in $K$. lactis than that obtained when the homologous $\mathrm{k} 1$ signal was employed.

When both INU1-based expression systems are compared in $K$. marxianus, it can be seen that the amounts of GOX produced were around the same level, slightly higher in the episomal construct $(\mathrm{Km} 2)$ than in the integrative one (Km3) (Table 2).

Considering that integration occurs preferably at a single copy in the genome and that replicative plasmids multiply autonomously in the cytoplasm, the similar GOX expression levels achieved in the two systems mentioned above are probably due to a combination of a higher copy number of pSPINGOX at the beginning of the cultivation and a concomitant loss of plasmids during the cultivation, when compared to the stable $\mathrm{Km} 3$ transformant (integrative). According to plasmid stability studies (data not shown), after $48 \mathrm{~h}$ of cultivation, both cells of $K$. marxianus and $K$. lactis nearly lost their episomal pSPGK1-derived plasmids.

Additional file 1 (Table S1) shows an overview of heterologous expression of Aspergillus niger GOX in different microorganisms. A direct comparison among the different expression systems is difficult, due to the different cultivation strategies used in each case. Taking this into account, the levels of GOX activity achieved in the present work with $K$. marxianus are in a low-tomiddle range, if we consider the highest $(30,000 \mathrm{U} / \mathrm{g}$ DW, assuming a final biomass concentration of $15 \mathrm{~g} / \mathrm{L}$ ) and the lowest $(27.9 \mathrm{U} / \mathrm{g} \mathrm{DW})$ values published (Additional file 1 - Table S1) [30,31]. However, since the aim of the present work was not to optimize the levels of heterologous GOX expression, there is probably much room for increasing these levels in further studies.

\section{Biochemical characterization of heterologous GOX}

The biochemical characterization of GOX performed here, in terms of molecular weight estimation using denaturing gels (Figure 2), activity under different $\mathrm{pH}$ values (Figure 3), stability towards $\mathrm{pH}$ (Figure 3 ), stability towards temperature (Figure 4), and in terms of the apparent Michaelis-Menten constant (Table 4) confirm that both yeasts were able to express and secrete the expected heterologous protein.

The $\mathrm{pH}$ for maximal activity lies between 5 and 6 for all cases investigated (Figure 3). The GOX activity-versus-pH profile, shown by the enzyme produced in $K$. marxianus, was closer to the standard enzyme in the range between the values of 3 and 7, when compared to the GOX produced by $K$. lactis. An optimum $\mathrm{pH}$ value of 5.5 was obtained by Zia et al. [32]. In alkaline $\mathrm{pH}$ values, the standard GOX is slightly more active than the ones expressed in either $K$. marxianus or $K$. lactis. The GOX secreted from $K$. marxianus has its structure partially affected at alkaline $\mathrm{pH}$ values, which becomes evident by its decreased activity, similarly to what occurs with the standard enzyme (Figure 3), since after 2 hours of exposure to these conditions, the activity of both enzymes could be restored by assaying the enzyme at the optimal pH (Figure 3B). The enzyme released from $K$. lactis is different, since its original activity was not fully restored under such conditions (Figure 3B). Thus, hyperglycosylation, an event that occurred to a higher extent in K. lactis than in K. marxianus (Figure 2), seems to provoke a conformational change that makes the protein irreversibly loose catalytic activity, especially during exposure to alkaline $\mathrm{pH}$ values (Figure $3 \mathrm{~B}$ ). Nevertheless, it is possible to affirm that, in general, the 
behavior of both heterologous enzymes is very similar to that of the standard GOX, mainly between $\mathrm{pH} 4$ and 8 .

In terms of stability towards temperature, all enzymes presented a similar behavior. All enzymes remain quite stable after 4 hours of incubation at $37^{\circ} \mathrm{C}$. At a temperature value above $55^{\circ} \mathrm{C}$, but below $60^{\circ} \mathrm{C}$, the stability of the enzyme starts to be strongly affected (Figure 4). A very similar thermal inactivation pattern was obtained by Gouda et al., who observed a significant loss of $A$. niger GOX activity at temperatures above $50^{\circ} \mathrm{C}$ [33].

The apparent Michaelis-Menten constants are all very similar, approaching the value obtained with the standard GOX (Table 4), which can be considered quite pure from the gels on Figure 2. There is not a consensus in literature concerning $\mathrm{GOX} \mathrm{K}_{\mathrm{M}}$ values. Wong et al. [29] reviewed several authors who published values ranging from $33 \mathrm{mM}$ (at $25^{\circ} \mathrm{C}$ ) to $248 \mathrm{mM}$ (at $30^{\circ} \mathrm{C}$ ). Zia et al. published a $\mathrm{K}_{\mathrm{M}}$ of $2.56 \mathrm{mM}$ (at $40^{\circ} \mathrm{C}$ ) for a GOX produced by $A$. niger UAF-1 [32]. The same authors obtained a $\mathrm{K}_{\mathrm{M}}$ of $28 \mathrm{mM}$ for the enzyme produced by $A$. niger BCG-5, a gamma radiation-mutant strain [34]. Mirón et al. estimated a value of $18 \mathrm{mM}$ (at $30^{\circ} \mathrm{C}$ ) [35]. Kohen et al. [26] calculated $\mathrm{K}_{M}$ to be 28 $\mathrm{mM}$ at $25^{\circ} \mathrm{C}$. This large dispersion of values is probably a consequence of the different conditions employed in the activity assays.

In Figure 2 it is possible to see that, after removal of the carbohydrate moiety of heterologous GOX with PNGase F, two bands appear on the gel corresponding to $K$. marxianus (indicated by the arrows), whereas only one band is visible on the gel corresponding to K. lactis. Since only one band is also visible after deglycosylation of the standard GOX with the same deglycosylating enzyme, this indicates that the glycosylation patterns in $K$. marxianus and $K$. lactis are different. It could be that in $K$. marxianus $\mathrm{O}$-glycosylation occurs, besides $\mathrm{N}$-glycosylation and that this is not the case for $K$. lactis $[36,37]$. Another observation is that the glycosylated

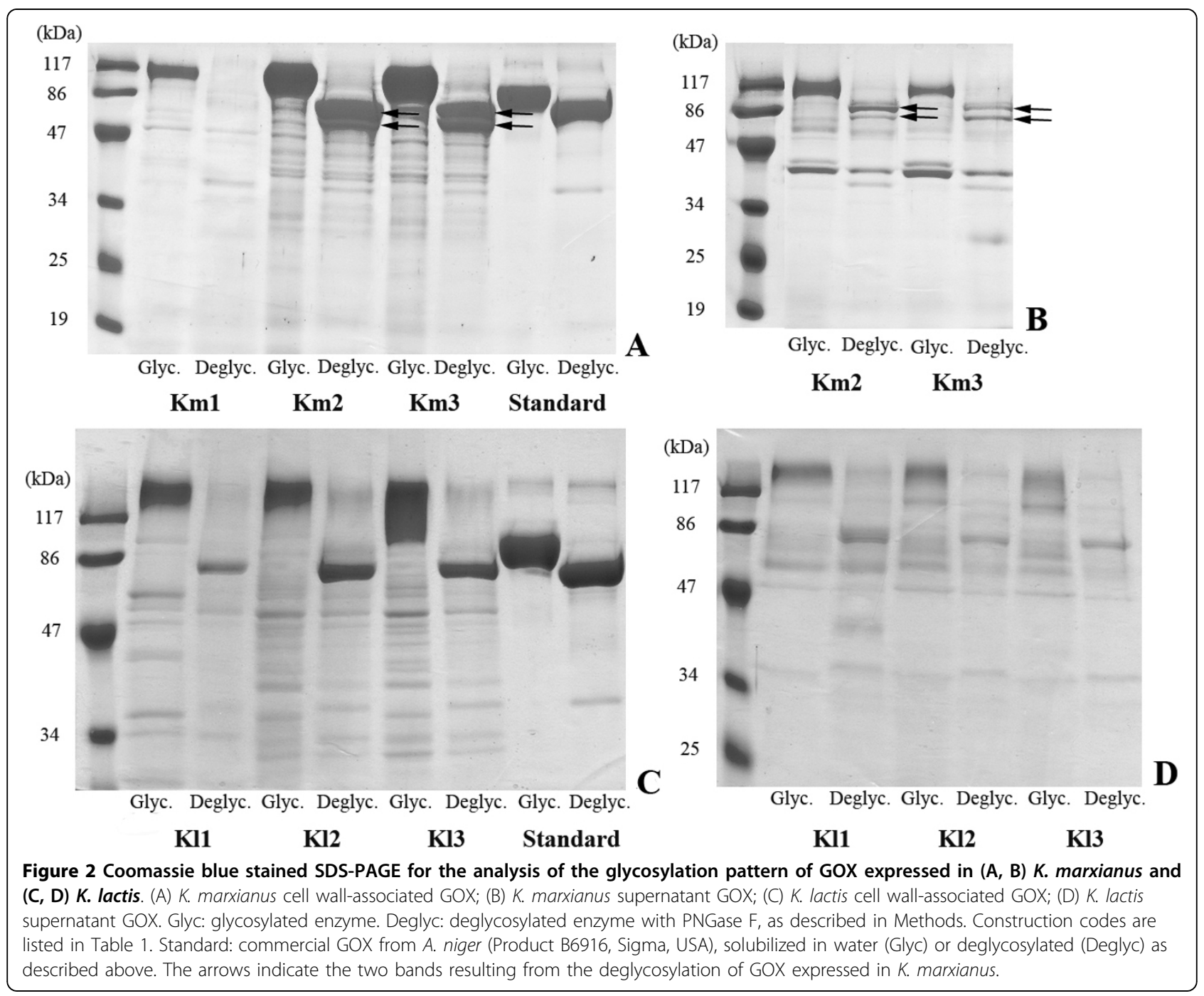




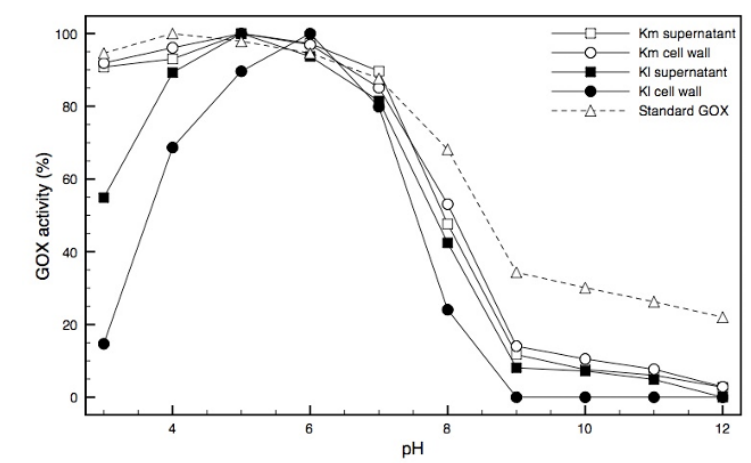

(A)

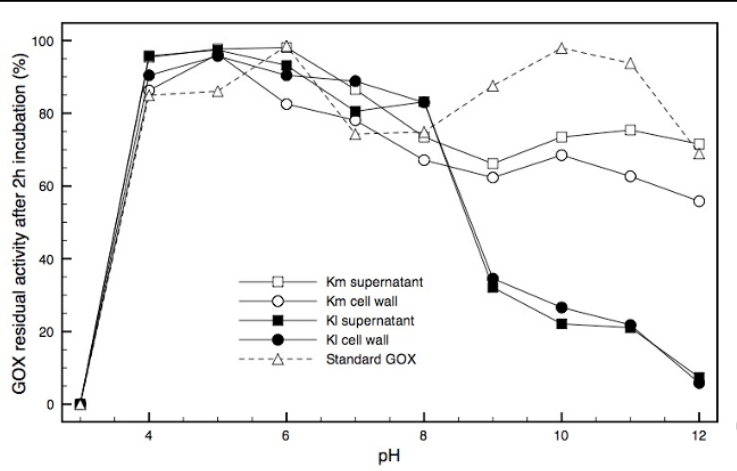

Figure 3 Effect of $\mathbf{p H}$ on heterologous GOX activity. (A) GOX activity was measured from $\mathrm{pH} 3$ to 12 ; and (B) residual GOX activity was measured after 2 hours of enzyme incubation at the corresponding $\mathrm{pH}$ (here, activity measurements were always carried out at $37^{\circ} \mathrm{C}$ and $\mathrm{pH}$ 4.5). The following buffers were used: acetate (3.0, 4.0, 5.0); HEPES (6.0, 7.0, 8.0); Tris (9.0, 10.0, 11.0, 12.0). Each point is the mean of a duplicate assay. Km supernatant and Km cell wall: GOX produced by Km2 construction. KI supernatant and KI cell wall: GOX produced by KI1 construction. Both clones were cultivated as described in the Methods section. Standard: commercial GOX from A. niger (Product B6916, Sigma, USA).

GOX in K. lactis has a higher molecular weight than the one in $K$. marxianus, indicating that the latter yeast has a lower tendency to hyperglycosylate proteins than the former, and consequentely also than S. cerevisiae [38]. Bergkamp et al. also observed a slightly higher molecular weight of the same alpha-galactosidase expressed in $S$. cerevisiae in comparison to the one produced by $K$. marxianus, which is most probably due to a higher glycosylation pattern in the former yeast [15]. Additional file 1 (Table S1) shows that GOX glycosylation levels in K. marxianus are close to the ones obtained in $H$. polymorpha, which are the lowest values obtained for heterologous GOX expression in yeasts $[39,40]$. It can also be seen from the gels (Figure 2) that the periplasmic and the fully secreted GOX have the same or at least a very similar molecular weight in both yeasts.

The bands corresponding to GOX in K. lactis are less sharp than the ones in $K$. marxianus. This could be due to some degradation of the enzyme during its extraction from the periplasmic space. When the lanes corresponding to the supernatant (Figure 2D) are compared to the lanes corresponding to the sample after extraction from the periplasmic space (Figure $2 \mathrm{C}$ ), it can be seen that there is much less non-specific protein in the former case, when compared to the latter. This is probably due to a general protein release from the periplasm during the extraction procedure.

The heterologous protein glycosylation pattern can be an important parameter when designing a commercial producing system. In the particular case of GOX, Kohen et al. [26] discuss that glycosylation does not affect the protein catalytic parameters (substrate binding and product releasing) when glucose is used as substrate. Moreover, the authors affirm that there is no evidence that glycosylation causes a major change in protein structure.
The notion that $K$. marxianus has a smaller tendency to hyperglycosylate heterologous proteins, when compared to other yeasts, needs to be confirmed by expressing other proteins in this organism and, in case it is confirmed, it would contribute to making this host attractive for the expression of therapeutic proteins.

\section{Conclusions}

We used the model protein glucose oxidase (GOX) from Aspergillus niger to evaluate the potential of the yeast $K$. marxianus to be used as a host for the production of heterologous proteins and to compare this system to the various heterologous GOX expression systems described in other organisms. Since GOX has eight potential sites for $N$-glycosylation, this enzyme also becomes suitable for a comparison of glycosylation levels in $K$. marxianus and in $K$. lactis. Besides this, it allows for an evaluation of how different glycosylation levels influence enzyme performance, mainly its activity and other biochemical properties, such as stability. For this purpose, we employed different episomal and integrative constructs, containing genetic elements either from $S$. cerevisiae in combination with elements from $K$. lactis or from $K$. marxianus. These expression systems were transformed into $K$. marxianus and $K$. lactis, in order to allow for a direct comparison of GOX expression in both yeasts. The biochemical characterization of the secreted enzyme, in terms of its localization, glycosylation pattern, $\mathrm{pH}$ range of activity, stability towards different temperatures and $\mathrm{pH}$ values, and apparent Michaelis constant, showed that GOX was expressed and secreted in active form in both species. The highest values of secreted GOX achieved were $1552 \mathrm{U} / \mathrm{g}$ dry cell weight of $K$. marxianus CBS 6556, using an episomal expression system with a promoter, prepro sequence and terminator of the homologous INU1 gene. GOX expression 

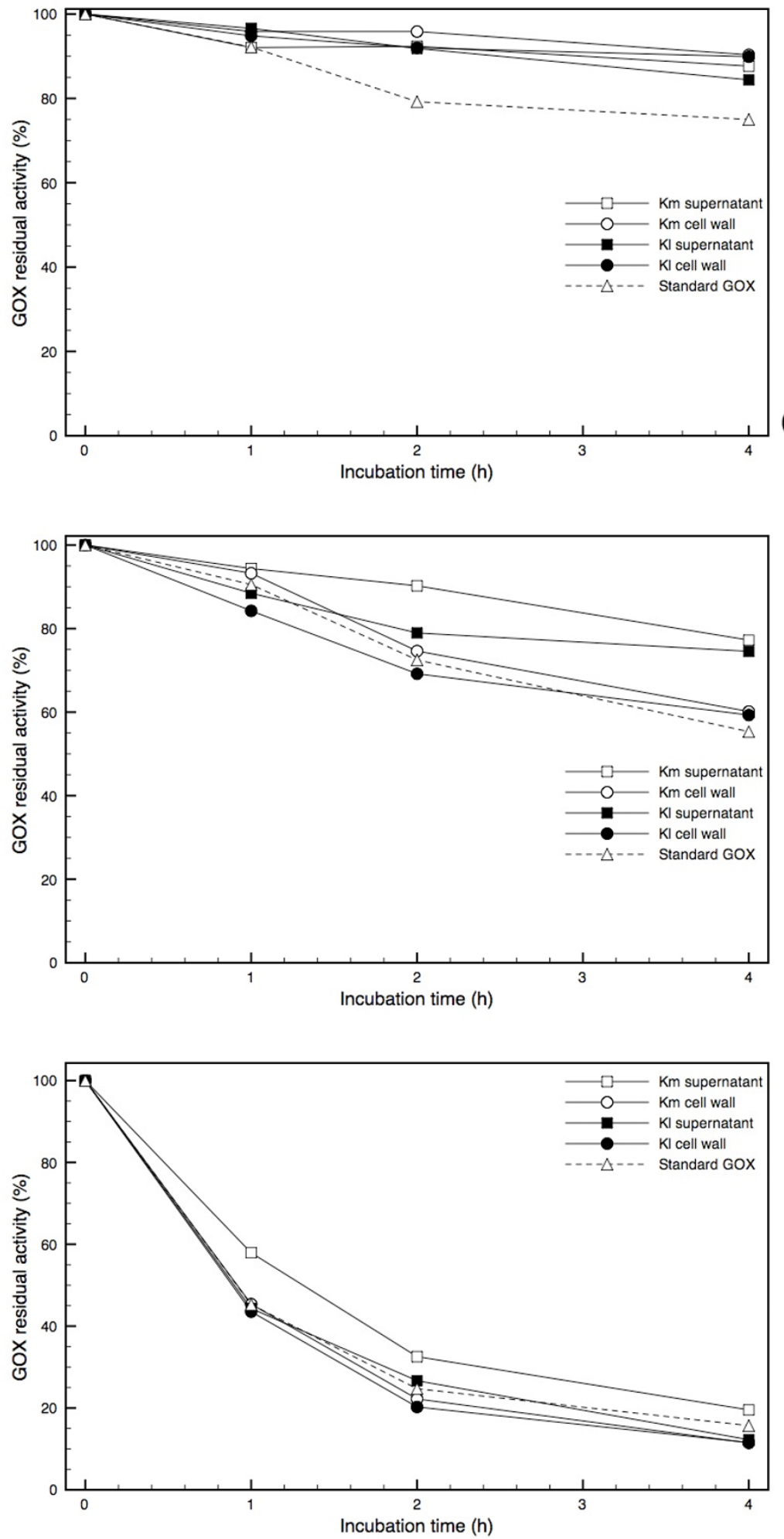

(C)

Figure $4 \mathrm{GOX}$ stability at different temperatures. Time course of residual $\mathrm{GOX}$ activity was measured after incubation at (A) $37^{\circ} \mathrm{C}$; (B) $55^{\circ} \mathrm{C}$, and $(\mathrm{C}) 60^{\circ} \mathrm{C}$. Activity measurements were always carried out at $37^{\circ} \mathrm{C}$ and $\mathrm{pH} 4.5$. Each point is the mean of a duplicate assay. The error bars show standard deviations. Km supernatant and Km cell wall: GOX produced by Km2 construction. KI supernatant and KI cell wall: GOX produced by KI1 construction. Both clones were cultivated as described in Methods section. Standard: commercial GOX from A. niger (Product B6916, Sigma, USA). 
Table $4 \mathrm{~K}_{\mathrm{M}(\mathrm{app})}$ values with respect to glucose.

\begin{tabular}{ll}
\hline GOX origin & $\mathbf{K}_{\mathbf{M} \text { (app) }}$ \\
\hline Km2 supernatant & $22.8 \mathrm{mM}$ \\
\hline Km2 cell wall & $17.4 \mathrm{mM}$ \\
Kl1 supernatant & $24.4 \mathrm{mM}$ \\
Kl1 cell wall & $22.6 \mathrm{mM}$ \\
Standard GOX & $16.4 \mathrm{mM}$ \\
\hline
\end{tabular}

List of GOX $K_{M}$ (app) determined from different constructions and fractions using the Lineweaver-Burk linearization method. $K_{M}$ (app) was determined as described in the Methods section.

based on INU1 genetic elements yielded higher levels in $K$. marxianus than in $K$. lactis. On the other hand, GOX expression based on the ScPGK promoter and terminator, in combination with the killer $\mathrm{k} 1$ secretion signal from $K$. lactis, led to higher levels in the latter yeast than in $K$. marxianus. $K$. lactis showed a higher capacity of GOX full secretion (in relative terms), when compared to $K$. marxianus, which retained more of the enzyme in the periplasm. In terms of glycosylation, it seems that the heterologous GOX expressed in K. marxianus was less hyperglycosylated than the one expressed in $K$. lactis and that hyperglycosylation did not negatively affect enzyme activity or stability. In conclusion, this paper provides data indicating that $K$. marxianus, which is a faster growing organism, more tolerant towards high temperatures and presenting a broader substrate range than its relative $K$. lactis, seems to be a suitable host for the production of glycosylated heterologous proteins.

\section{Methods}

\section{Strains and media}

Escherichia coli strain DH10b (Invitrogen, USA) was used for plasmids construction and propagation. Kluveromyces marxianus CBS 6556 was purchased from Centraal Bureau voor Schimmelcultures (Ultrecht, The Netherlands). Kluveromyces lactis PM5-3C (MATa uraA $\mathrm{Rag}^{+}$) was kindly provided by Dr. Micheline Wesolowski-Louvel (Lyon, France). Saccharomyces cerevisiae

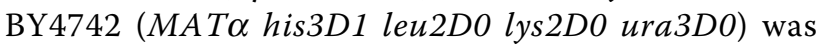
provided by Euroscarf (Frankfurt, Germany) [41]. The strain $K$. marxianus SLC33 is an ura3 mutant from $K$. marxianus CBS 6556, obtained in this work by selection in 5-FOA-containing plates (ura-phenotype stability was certified for up to 120 generations).

E. coli strains were grown on LB (1\% bacto-tryptone, $0.5 \%$ yeast extract, $0.5 \% \mathrm{NaCl}, 0.1 \%$ glucose) liquid or solid ( $2 \%$ bacto-agar) media at $37^{\circ} \mathrm{C}$. Ampicilin $(40 \mathrm{mg} /$ $\mathrm{L}$ final concentration) was added for plasmid selection. For the selection of yeast transformants exhibiting $U R A 3$ expression, complete medium (CM) lacking uracyl (CM-URA) was used [42]. 5-FOA plates for selection of ura3 mutants were made as described in [43]. A first screening of GOX-expressing yeasts was performed in YPHSM-SUC medium, which contains (in $\mathrm{g} \mathrm{l}^{-1}$ ): peptone (80), yeast extract (10), glycerol (30), sucrose (10). For the GOX expression studies, strains were grown on the defined medium (DM) described by [44], and subsequently on YPS complex medium (1\% yeast extract, $2 \%$ bacto-peptone, $2 \%$ sucrose).

\section{Isolation and manipulation of nucleic acids}

Plasmid DNA from E. coli was obtained using the Spin Clean Plasmid Miniprep Kit (Mbiotech, South Corea). Plasmid DNA from yeast cells was prepared using the same kit of bacterial mini-prep, differing in some steps of the protocol, as follows: yeast cells containing the plasmid of interest were harvested from a 24-hour, 10 $\mathrm{mL}$ culture on CM medium, by centrifugation $(3000 \times$ g, $5 \mathrm{~min}$ ). The pellet was resuspended in $250 \mu \mathrm{L}$ of the resuspension buffer and $250 \mu \mathrm{L}$ of the lysis buffer (provided with the kit) and approximately $250 \mu \mathrm{L}$ of glass beads (425-600 $\mu \mathrm{m}$, Sigma, USA). The mixture was vortexed vigorously for 2 minutes and maintained in ice for other 5 minutes. Afterward, the ordinary mini-prep protocol was followed. The final DNA suspension was used directly for E. coli transformation and plasmid propagation. Yeast transformation by the lithium acetate method was performed as described by [45]. Furthermore, yeast transformation by electroporation was adapted from the protocol described by [46], as follows. $10 \mathrm{~mL}$ of a yeast culture in early exponential phase were centrifuged $(4000 \times \mathrm{g}, 5 \mathrm{~min})$ and washed with $1 \mathrm{~mL}$ of ultrapure water. Subsequently, cells were resuspended in $1 \mathrm{~mL}$ of pre-treatment buffer (YPD, $200 \mathrm{mM}$ DTT, 300 $\mathrm{mM}$ HEPES) and incubated at $30^{\circ} \mathrm{C}$ for 30 minutes. Then, cells were centrifuged $(4000 \times \mathrm{g}, 5 \mathrm{~min})$ and resuspended in $1 \mathrm{~mL}$ of electroporation buffer $(10 \mathrm{mM}$ Tris- $\mathrm{HCl} \mathrm{pH} \mathrm{7.5,} 270 \mathrm{mM}$ sucrose, $1 \mathrm{mM}$ lithium acetate). The electric shock was carried out using the following parameters: $25 \mu \mathrm{F}, 550 \mathrm{~V}$, and $600 \Omega$.

PCR reactions were carried out in a final volume of 25 $\mu \mathrm{L}$ of reaction mixture which consisted of $20 \mathrm{ng}$ of DNA template, $30 \mathrm{pmol}$ of each primer (Table 5), 1.75 nmol of each dNTPs, $50 \mathrm{mM} \mathrm{KCl,} 2.5 \mathrm{mM} \mathrm{MgCl}_{2}, 0.25$ $\mathrm{U}$ of Taq DNA polymerase (Roche Diagnostistics, Mannheim, Germany) in $10 \mathrm{mM}$ Tris-HCl buffer, $\mathrm{pH}$ 8.3. The reactions were proceeded in 30 cycles: denaturation was at $94^{\circ} \mathrm{C}$ for 30 seconds, annealing at $50^{\circ} \mathrm{C}$ (for the GOX gene) and at $53^{\circ} \mathrm{C}$ (for the INU1 cassette) for 60 seconds, and extension at $72^{\circ} \mathrm{C}$ for 2.5 minutes (GOX) and 3 minutes (INU1). All other DNA manipulations were performed as described by [47].

\section{Plasmids construction and yeast transformation}

The episomal expression vector pSPGOX (Fig. 1A) was constructed as follows. The GOX gene of A. niger BT18 was amplified by PCR from the plasmid pBT86 (obtained from Dr. Oscar Bañuelos, Puleva Biotech Inc., 
Table 5 Primers.

\begin{tabular}{|c|c|c|}
\hline Primer ID & Sequence & Details \\
\hline PSPGOXF & 5' - TITTGGCTGTCATTCGTTCAAGGTAAAAGAAGCAATGGCATTGAAGCC & $\begin{array}{l}\text { Underlined sequence is homologous to the last bases of } \\
\text { K. lactis killer protein } \mathrm{k} 1 \text { secretion signal sequence }\end{array}$ \\
\hline PSPGOXR & 5' - CACCACCACCAGTAGAGACATGGGAGATCGTCACTGCATGGAAGCATA & $\begin{array}{l}\text { Underlined sequence is homologous to the first bases of } \\
\text { S. cerevisiae PGK terminator }\end{array}$ \\
\hline PINU1Fb & 5'- GGATCCGAATTCTCAAACCGAAATGGG & Underlined extremity is an added BamHI restriction site \\
\hline PINU1Rb & 5'- GGATCCACGCCAGACGTCTTGTGTCCG & Underlined extremity is an added BamHI restriction site \\
\hline PINUGOXF & 5' -GTCAGTGCTTCAGTTATCAATTACAAGAGA AGCAATGGCATTGAAGCC & $\begin{array}{l}\text { Underlined sequence is homologous to the last bases of } \\
\text { K. marxianus INU1 secretion signal sequence }\end{array}$ \\
\hline PINUGOXR & 5'- TाTTGTCGTTAGTAAAGTAAGCAGATCAGA TCACTGCATGGAAGCATA & $\begin{array}{l}\text { Underlined sequence is homologous to the last bases of } \\
\text { K. marxianus INU1 terminator }\end{array}$ \\
\hline
\end{tabular}

List of primers used on DNA constructions.

Spain) using the primers PSPGOXF and PSPGOXR (Table 5). The amplified $1.8 \mathrm{~kb}$ fragment was cloned into the replicative plasmid pSPGK1 [48]. This plasmid possesses the $K$. lactis S11 origin of replication and owns the ability to replicate in $K$. marxianus and $K$. lactis cells. The insertion of GOX CDS was performed by homologous recombination of the PCR product with pSPGK1 linearized with EcoRI. Equal amounts of plasmid and insert (500 ng) were used to transform $K$. lactis PM5-3C by the lithium acetate method. Transformants showed ability to grow on CM-URA selective medium. Confirmation of recombination was perfomed by PCR, amplifying the GOX fragment from the plasmids with PSPGOXF and PSPGOXR and by the extracellular expression of glucose oxidase by top-agar plate assay described by [49]. Hence, plasmids were extracted from $K$. lactis cells and used to transform $K$. marxianus SLC33 by the lithium acetate method.

The constructions using INU1 cassette for GOX expression started with amplification of the INU1 cassette from the chromosomal DNA of $K$. marxianus CBS 6556 using primers PINU1Fb and PINU1Rb (Table 5). Both primers have in the 5' extremities a BamHI restriction site. After amplification, the INU1 cassette was ligated to the pMBL1-T (MBiotech, South Korea) vector for propagation. Thus, the insert was excised by BamHI restriction. Later, this cassette was cloned into the yeastE. coli shuttle vector Yeplac195, and the resulting construct linearized with Tth111I. In parallel, GOX from pBT86 was amplified using primers PINUGOXF and PINUGOXR (Table 5). These two primers were capable to add extremities to the amplified gene, which were homologous to INU1 secretion signal and terminator sequences. The resulting fragment was cloned into pMBL1-T for propagation. For recombination, the linearized Yeplac195 and the amplified GOX carrying homologous extremities were fused by homologous recombination in S. cerevisiae BY4742 transformed with an equal proportion of both plasmid and insert (500 ng) by the lithium acetate method. The construction was purified from $S$. cerevisiae cells and digested with
BamHI, which released the GOX expression cassette. After propagation of the $3.4 \mathrm{~kb}$ cassette in pMBL1-T, this fragment was subcloned into the BamHI site of pSPGK1 and pNADFL11, resulting in the episomal and integrative constructions shown in Figures $1 \mathrm{~B}$ and $1 \mathrm{C}$, respectively.

The expression vectors were used to transform $K$. marxianus SLC33 and K. lactis PM5-3C by the lithium acetate method, with exception of the integrative construction in $K$. marxianus. In this case, the yeast was transformed by electroporation, since the lithium acetate method was ineffective. The resulting constructs are detailed on Table 1 and Figure 1.

After transformation of yeast cells with each construction, transformants that showed higher extracellular GOX activity were selected by top-agar. Colonies exhibiting higher activities were surrounded by a larger brownish halo. The three transformants showing higher activities of each construct were selected. Thus, the chosen candidates were grown in liquid YPHSM-SUC medium for $36 \mathrm{~h}$ and GOX activity measured. The candidates that exhibited the higher activity for each construct were selected for the further studies.

\section{Analysis of glucose oxidase production in submerged cultivations}

The cultivation conditions described by [15], which resulted in the efficient secretory production of a heterologous alpha-galactosidase in $K$. marxianus, were adopted with slight modifications. Transformants were grown in baffled $500 \mathrm{~mL}$ shake flasks closed with cotton on an orbital shaker (300 rpm), using $100 \mathrm{~mL}$ of medium at $30^{\circ} \mathrm{C}$. First, the cells were grown for $24 \mathrm{~h}$ in the defined medium DM (using 2\% glucose as carbon source). Second, these cells were diluted 1:10 into fresh YPS medium and grown for another $48 \mathrm{~h}$. All cultivations were performed in duplicate. Subsequently, the heterologous enzyme present in the supernatant, in the cell wall (retained inside the periplasmic space), and the cellbound (intracellular) fractions were separated based on the method described by Rouwenhorst et al. [50]. The solubilization of cell wall-associated enzyme was induced 
by suspension of the cells in $10 \mathrm{~mL}$ of enzyme release buffer $(50 \mathrm{mM}$ potassium phosphate, $\mathrm{pH} 7,10 \mathrm{mM} 2$ mercaptoethanol, $10 \mathrm{mM}$ dithiotheitol, $2 \mathrm{mM} \mathrm{MgSO}_{4}$ ). The cell-bound enzyme was liberated incubating cells in $100 \mathrm{mM}$ phosphate buffer containing $2 \mathrm{mM} \mathrm{MgCl}_{2}, 2 \%$ DTT and 5\% protease inhibitor cocktail (Product no. P8215, Sigma, USA). Glass beads (425-600 m) were added, and total cell disruption was performed by vortexing the mixture five times for 1 minute (with 1 min interval, incubated in ice). Cell debris was separated by centrifugation and the supernatant contained the cellbound enzyme. GOX activity was determined spectrophotometrically in the three fractions, relative to a standard curve of absorbance vs enzyme activity, by the odianisidine reduction method [49]. Protein content in all the fractions was measured by the Bradford method (product B6916, Sigma, USA), with bovine serum albumin as standard, according to the instructions of the manufacturer. The dry cell weight of $5 \mathrm{~mL}$ sample of each culture flask was determined using $0.45 \mu \mathrm{m}$ membrane filters and a microwave oven (180 W, $15 \mathrm{~min})$ [51].

\section{GOX glycosylation analysis}

The glucose oxidase expressed by the six different constructions of $K$. marxianus and $K$. lactis (Table 1 ) was analyzed with respect to the degree of glycosylation in the supernatant and in the cell wall fractions (the cellbound fraction was always very small, compared to the two other fractions). For this purpose, the supernatant and cell wall fractions were concentrated in $10 \mathrm{kDa}$ cutoff ultrafilters (Millipore, USA). To de-glycosylate GOX, $15 \mu \mathrm{g}$ of the protein were denaturated by incubation for $5 \mathrm{~min}$ at $100^{\circ} \mathrm{C}$ in $10 \mu \mathrm{L}$ final volume reaction containing $0.5 \% \mathrm{SDS}$ and $40 \mathrm{mM}$ 2-mercaptoethanol. After cooling, Tergitol NP-40, sodium phosphate buffer $\mathrm{pH}$ 7.5, and PNGase F (New England Biolabs, USA) were added to final concentrations of $1 \%, 50 \mathrm{mM}$, and $5 \mathrm{U} /$ $\mu \mathrm{L}$, in a $20 \mu \mathrm{L}$ final volume reaction. The mixture was incubated for 1 hour at $37^{\circ} \mathrm{C}$. Migration patterns of both glycosylated and deglycosylated forms of GOX were compared on a $10 \%$ SDS-PAGE gel carried out as described by Laemmli [52] and stained with coomassie blue.

\section{GOX biochemical characterization}

The enzyme synthesized by the transformant of each species, either $K$. marxianus or $K$. lactis, that exhibited the highest biomass specific activity in both fractions (supernatant and cell wall) was subjected to a biochemical characterization, in which the $\mathrm{pH}$ of optimal activity and the stability at different $\mathrm{pH}$ and temperature values were examined. GOX activity was measured at the following $\mathrm{pH}$ values: $3.0,4.0,5.0$ (50 $\mathrm{mM}$ acetate buffer); 6.0, 7.0, and 8.0 (50 mM HEPES buffer); 9.0, 10.0, 11.0, 12.0 (50 mM Tris buffer). In each buffer, glucose was mixed to a final concentration of $100 \mathrm{mM}, 2 \mathrm{U}$ horseradish peroxidase (Type II, Sigma, USA), and odianisidine di-hydrochloride to a final concentration of $100 \mu \mathrm{M}$. The thermal stability was determined during four hours of incubation at $37^{\circ} \mathrm{C}, 55^{\circ} \mathrm{C}$, and $60^{\circ} \mathrm{C}$ at $\mathrm{pH}$ 4.5. Samples were taken at 0, 1, 2 and 4 hours of incubation and the enzyme activity was measured immediately at $37^{\circ} \mathrm{C}$ and $\mathrm{pH} 4.5$. Stability towards $\mathrm{pH}$ was determined after incubating the enzyme for 2 hours at $37^{\circ} \mathrm{C}$ in the buffers mentioned above (from pH 3.0 to 12.0). Samples were immediately assayed for enzyme activity at $\mathrm{pH} 4.5$. For the $\mathrm{K}_{\mathrm{M}}$ (app) determination, the supernatant and cell wall fractions were purified in a Sephacryl S-300-HR gel-permeation column, in order to eliminate reactive contaminants. Samples were eluted at $0.5 \mathrm{~mL} / \mathrm{min}$ in $50 \mathrm{mM}$ citrate buffer $(\mathrm{pH} 4.8) . \mathrm{K}_{\mathrm{M}}$ (app) was determined measuring the lambda absorbance per minute increase at $30^{\circ} \mathrm{C}$, incubating the enzyme with 50 mM McIlvane's buffer, 2 U horseradish peroxidase (Type II, Sigma, USA), and $100 \mu \mathrm{M}$ o-dianisidine dihydrochloride, and glucose in the following concentrations: $2 \mathrm{mM}, 5 \mathrm{mM}, 10 \mathrm{mM}, 15 \mathrm{mM}, 20 \mathrm{mM}, 30 \mathrm{mM}$, $50 \mathrm{mM}, 75 \mathrm{mM}, 100 \mathrm{mM}$. All biochemical assays were also performed with a commercial A. niger GOX (G6125, Sigma, USA), considered here as a standard.

Additional file 1: Table S1 - Different systems for GOX expression Overview of different microbial systems employed for the heterologous expression of Aspergillus niger glucose oxidase.

Click here for file

[ http://www.biomedcentral.com/content/supplementary/1475-2859-9-4S1.DOC ]

\section{Acknowledgements}

We would like to thank Dr. Oscar Bañuelos (Puleva Biotech, Spain) for the kind gift of the plasmid containing the GOX gene from Aspergillus niger, Dr. Nancy da Silva (University of California at Irvine) for kindly providing us the pNADFL11 plasmid, Dr. Hiroshi Fukuhara for providing the PSPGK1 plasmid, and Dr. Wésolowski-Louvel for kindly donating the K. lactis PM5-3C strain. SNR acknowledges grants received from Fundação de Amparo à Pesquisa do Estado de São Paulo (FAPESP, São Paulo, Brazil) and from Coordenadoria de Aperfeiçoamento de Pessoal de Nível Superior (CAPES, Brasília, Brazil), which made possible a one-year internship of the researcher at the Biochemistry and Molecular Biology Laboratory of Universidade da Coruña (Spain), where the DNA work was carried out. This work was financially supported by FAPESP and by Conselho Nacional de Desenvolvimento Científico e Tecnológico (CNPq, Brasília, Brazil), and by Xunta de Galicia (Proyecto PGIDIT06REM38302PR, Spain).

\section{Author details}

'Department of Chemical Engineering, Polytechnic School of Engineering, University of São Paulo, CP 61548, 05424-970 São Paulo-SP, Brazil. ${ }^{2}$ School of Pharmaceutical Sciences, University of São Paulo, Av Prof Lineu Prestes, 580bloco 16, 05508-900 São Paulo-SP, Brazil. ${ }^{3}$ Departamento de Bioloxía Celular e Molecular, Facultade de Ciencias, Universidade da Coruña, Campus da Zapateira s/n, 15071-A Coruña, Spain.

\section{Authors' contributions}

SNR participated in the design of this study, carried out the practical experiments, data analysis and drafted part of the manuscript. JA-N participated in designing and executing the GOX biochemical 
characterization and glycosylation studies, in the analysis of results, reviewing and commenting the manuscript. MEC participated in reviewing and commenting the manuscript. MIG-S designed and supervised all DNA construction strategies, and participated in the analysis of results, writing, reviewing and commenting the manuscript. AKG conceived the study, designed the cultivations, participated in the analysis of results, writing, reviewing and commenting the manuscript. All authors have read and approved the manuscript.

\section{Competing interests}

The authors declare that they have no competing interests.

Received: 3 August 2009

Accepted: 21 January 2010 Published: 21 January 2010

\section{References}

1. Bellaver LH, de Carvalho NM, Abrahao-Neto J, Gombert AK: Ethanol formation and enzyme activities around glucose-6-phosphate in Kluyveromyces marxianus CBS 6556 exposed to glucose or lactose excess. FEMS Yeast Res 2004, 4(7):691-698.

2. Kiers J, Zeeman AM, Luttik M, Thiele C, Castrillo Jl, Steensma HY, van Dijken JP, Pronk JT: Regulation of alcoholic fermentation in batch and chemostat cultures of Kluyveromyces lactis CBS 2359. Yeast 1998, 14(5):459-469.

3. van Ooyen AJ, Dekker P, Huang M, Olsthoorn MM, Jacobs DI, Colussi PA, Taron $\mathrm{CH}$ : Heterologous protein production in the yeast Kluyveromyces lactis. FEMS Yeast Res 2006, 6(3):381-392.

4. Fonseca GG, Heinzle E, Wittmann C, Gombert AK: The yeast Kluyveromyces marxianus and its biotechnological potential. Appl Microbiol Biotechnol 2008, 79(3):339-354.

5. Fonseca GG, Gombert AK, Heinzle E, Wittmann C: Physiology of the yeast Kluyveromyces marxianus during batch and chemostat cultures with glucose as the sole carbon source. FEMS Yeast Res 2007, 7(3):422-435.

6. Groeneveld P, Stouthamer AH, Westerhoff HV: Super life-how and why 'cell selection' leads to the fastest-growing eukaryote. The FEBS journal 2009, 276(1):254-270

7. Cox H, Mead D, Sudbery P, Eland RM, Mannazzu I, Evans L: Constitutive expression of recombinant proteins in the methylotrophic yeast Hansenula polymorpha using the PMA1 promoter. Yeast 2000, 16(13):1191-1203.

8. Daly R, Hearn MT: Expression of heterologous proteins in Pichia pastoris: a useful experimental tool in protein engineering and production. $\mathrm{J} \mathrm{Mol}$ Recognit 2005, 18(2):119-138.

9. Madzak C, Otterbein L, Chamkha M, Moukha S, Asther M, Gaillardin C, Beckerich JM: Heterologous production of a laccase from the basidiomycete Pycnoporus cinnabarinus in the dimorphic yeast Yarrowia lipolytica. FEMS Yeast Res 2005, 5(6-7):635-646.

10. Muller $\mathrm{S}$, Sandal $\mathrm{T}$, Kamp-Hansen $\mathrm{P}$, Dalboge $\mathrm{H}$ : Comparison of expression systems in the yeasts Saccharomyces cerevisiae, Hansenula polymorpha, Kluyveromyces lactis, Schizosaccharomyces pombe and Yarrowia lipolytica. Cloning of two novel promoters from Yarrowia lipolytica. Yeast 1998, 14(14):1267-1283.

11. Porro D, Sauer M, Branduardi P, Mattanovich D: Recombinant protein production in yeasts. Mol Biotechnol 2005, 31(3):245-259.

12. Wildt $\mathrm{S}$, Gerngross TU: The humanization of N-glycosylation pathways in yeast. Nat Rev Microbiol 2005, 3(2):119-128.

13. Hamilton SR, Gerngross TU: Glycosylation engineering in yeast: the advent of fully humanized yeast. Curr Opin Biotechnol 2007, 18(5):387-392.

14. Raimondi S, Uccelletti D, Matteuzzi D, Pagnoni UM, Rossi M, Palleschi C: Characterization of the superoxide dismutase SOD1 gene of Kluyveromyces marxianus $\mathrm{L} 3$ and improved production of SOD activity. Appl Microbiol Biotechnol 2008, 77(6):1269-1277.

15. Bergkamp RJ, Bootsman TC, Toschka HY, Mooren AT, Kox L, Verbakel JM, Geerse RH, Planta RJ: Expression of an alpha-galactosidase gene under control of the homologous inulinase promoter in Kluyveromyces marxianus. Appl Microbiol Biotechnol 1993, 40(2-3):309-317.

16. Ball MM, Raynal A, Guerineau M, Iborra F: Construction of efficient centromeric, multicopy and expression vectors for the yeast Kluyveromyces marxianus using homologous elements and the promoter of a purine-cytosine-like permease. J Mol Microbiol Biotechnol 1999, 1(2):347-353.
17. Almeida C, Queiros O, Wheals A, Teixeira J, Moradas-Ferreira P: Acquisition of flocculation phenotype by Kluyveromyces marxianus when overexpressing GAP1 gene encoding an isoform of glyceraldehyde-3phosphate dehydrogenase. J Microbiol Methods 2003, 55(2):433-440.

18. Pecota DC, Da Silva NA: Evaluation of the tetracycline promoter system for regulated gene expression in Kluyveromyces marxianus. Biotechnol Bioeng 2005, 92(1):117-123.

19. Cai XP, Zhang J, Yuan HY, Fang ZA, Li YY: Secretory expression of heterologous protein in Kluyveromyces cicerisporus. Applied Genetics and Molecular Biotechnology 2005, 67:364-369.

20. Pecota DC, Rajgarhia V, Da Silva NA: Sequential gene integration for the engineering of Kluyveromyces marxianus. J Biotechnol 2007, 127(3):408416.

21. Hong J, Wang $Y$, Kumagai $H$, Tamaki H: Construction of thermotolerant yeast expressing thermostable cellulase genes. J Biotechnol 2007, 130(2):114-123.

22. Nonklang S, Abdel-Banat BM, Cha-Aim K, Moonjai N, Hoshida H, Limtong S, Yamada M, Akada R: High-temperature ethanol fermentation and transformation with linear DNA in the thermotolerant yeast Kluyveromyces marxianus DMKU3-1042. Appl Environ Microbiol 2008, 74(24):7514-7521.

23. Siekstele R, Bartkeviciute D, Sasnauskas K: Cloning, targeted disruption and heterologous expression of the Kluyveromyces marxianus endopolygalacturonase gene (EPG1). Yeast 1999, 15(4):311-322.

24. Schwan RF, Cooper RM, Wheals AE: Endopolygalacturonase secretion by Kluyveromyces marxianus and other cocoa pulp-degrading yeasts. Enzyme Microb Technol 1997, 21:234-244.

25. Rouwenhorst RJ, Ritmeester WS, Scheffers WA, Van Dijken JP: Localization of inulinase and invertase in Kluyveromyces species. Appl Environ Microbiol 1990, 56(11):3329-3336

26. Kohen A, Jonsson T, Klinman JP: Effects of protein glycosylation on catalysis: changes in hydrogen tunneling and enthalpy of activation in the glucose oxidase reaction. Biochemistry 1997, 36(9):2603-2611.

27. Frederick KR, Tung J, Emerick RS, Masiarz FR, Chamberlain SH, Vasavada A Rosenberg S, Chakraborty S, Schopfer LM, et al: Glucose oxidase from Aspergillus niger. Cloning, gene sequence, secretion from Saccharomyces cerevisiae and kinetic analysis of a yeast-derived enzyme. The Journal of biological chemistry 1990, 265(7):3793-3802.

28. Bergkamp RJ, Kool IM, Geerse RH, Planta RJ: Multiple-copy integration of the alpha-galactosidase gene from Cyamopsis tetragonoloba into the ribosomal DNA of Kluyveromyces lactis. Current genetics 1992, 21(4-5):365370.

29. Wong $\mathrm{CM}$, Wong $\mathrm{KH}$, Chen XD: Glucose oxidase: natural occurrence, function, properties and industrial applications. Appl Microbiol Biotechnol 2008, 78(6):927-938.

30. Park EH, Shin YM, Lim YY, Kwon TH, Kim DH, Yang MS: Expression of glucose oxidase by using recombinant yeast. J Biotechnol 2000, 81(1):3544.

31. Hellmuth K, Pluschkell S, Jung JK, Ruttkowski E, Rinas U: Optimization of glucose oxidase production by Aspergillus niger using genetic- and process-engineering techniques. Appl Microbiol Biotechnol 1995, 43(6):978984.

32. Zia MA, Khalil-ur-Rahman, Saeed MK, Andaleeb F, Rajoka MI, Sheikh MA, Khan IA, Khan Al: Thermal characterization of purified glucose oxidase from a newly isolated Aspergillus niger UAF-1. Journal of Clinical Biochemistry and Nutrition 2007, 41(2):132-138.

33. Gouda MD, Singh SA, Rao AG, Thakur MS, Karanth NG: Thermal inactivation of glucose oxidase. Mechanism and stabilization using additives. The Journal of biological chemistry 2003, 278(27):24324-24333.

34. Zia MA, Khalil-ur-Rahman, Saeed MK, Anjum F: Thermal characterization of hyperproduced glucose oxidase from Aspergillus niger BCG-5 mutant strain. 2007 leee/lcme International Conference on Complex Medical Engineering 2007, 1-4:1950-1955.

35. Mirón J, González MP, Pastrana L, Murado MA: Diauxic production of glucose oxidase by Aspergillus niger in submerged culture A dynamic model. Enz Microb Technol 2002, 31:615-620.

36. Strahl-Bolsinger S, Gentzsch M, Tanner W: Protein O-mannosylation. Biochim Biophys Acta 1999, 1426(2):297-307.

37. Lommel M, Strahl S: Protein O-Mannosylation: Conserved from Bacteria to Humans. Glycobiology 2009, 19(8):816-828. 
38. Chiba Y, Jigami Y: Production of humanized glycoproteins in bacteria and yeasts. Curr Opin Chem Biol 2007, 11(6):670-676.

39. Kim MW, Rhee SK, Kim JY, Shimma Y, Chiba Y, Jigami Y, Kang HA: Characterization of $\mathrm{N}$-linked oligosaccharides assembled on secretory recombinant glucose oxidase and cell wall mannoproteins from the methylotrophic yeast Hansenula polymorpha. Glycobiology 2004, 14(3):243-251.

40. Kim SY, Sohn JH, Pyun YR, Choi ES: Variations in protein glycosylation in Hansenula polymorpha depending on cell culture stage. J Microbiol Biotechnol 2007, 17(12):1949-1954.

41. Brachmann CB, Davies A, Cost GJ, Caputo E, Li J, Hieter P, Boeke JD: Designer deletion strains derived from Saccharomyces cerevisiae S288C: a useful set of strains and plasmids for PCR-mediated gene disruption and other applications. Yeast 1998, 14(2):115-132.

42. Zitomer RS, Hall BD: Yeast cytochrome $\mathrm{c}$ messenger RNA. In vitro translation and specific immunoprecipitation of the $C Y C 1$ gene product. The Journal of biological chemistry 1976, 251(20):6320-6326.

43. Boeke JD, LaCroute F, Fink GR: A positive selection for mutants lacking orotidine-5'-phosphate decarboxylase activity in yeast: 5 -fluoro-orotic acid resistance. Mol Gen Genet 1984, 197(2):345-346.

44. Verduyn C, Postma E, Scheffers WA, Van Dijken JP: Effect of benzoic acid on metabolic fluxes in yeasts: a continuous-culture study on the regulation of respiration and alcoholic fermentation. Yeast 1992, 8(7):501517.

45. Ito H, Fukuda Y, Murata K, Kimura A: Transformation of intact yeast treated with alkali cations. J Bacteriol 1983, 153:163-168.

46. Kooistra R, Hooykaas PJ, Steensma HY: Efficient gene targeting in Kluyveromyces lactis. Yeast 2004, 21:781-792.

47. Sambrook J, Russel DW: Molecular Cloning: A laboratory manual. New York: Cold Spring Harbor Laboratory Press 2001.

48. Fleer $R$, Yeh P, Amellal N, Maury I, Fournier A, Bacchetta F, Baduel P, Jung G, L'Hote H, Becquart J, et al: Stable multicopy vectors for high-level secretion of recombinant human serum albumin by Kluyveromyces yeasts. Biotechnology (NY) 1991, 9(10):968-975.

49. Malherbe DF, du Toit M, Cordero Otero RR, van Rensburg P, Pretorius IS: Expression of the Aspergillus niger glucose oxidase gene in Saccharomyces cerevisiae and its potential applications in wine production. Appl Microbiol Biotechnol 2003, 61(5-6):502-511.

50. Rouwenhorst RJ, Visser LE, Baan Van Der AA, Scheffers WA, Van Dijken JP: Production, Distribution, and Kinetic Properties of Inulinase in Continuous Cultures of Kluyveromyces marxianus CBS 6556. Appl Environ Microbiol 1988, 54(5):1131-1137.

51. Olsson L, Nielsen J: On-line and in situ monitoring of biomass in submerged cultivations. TIBTECH 1997, 15:517-522.

52. Laemmli UK: Cleavage of structural proteins during the assembly of the head of bacteriophage T4. Nature 1970, 227(5259):680-685.

doi:10.1186/1475-2859-9-4

Cite this article as: Rocha et al:: Heterologous expression of glucose oxidase in the yeast Kluyveromyces marxianus. Microbial Cell Factories 2010 9:4.

Publish with Bio Med Central and every scientist can read your work free of charge

"BioMed Central will be the most significant development for disseminating the results of biomedical research in our lifetime. "

Sir Paul Nurse, Cancer Research UK

Your research papers will be:

- available free of charge to the entire biomedical community

- peer reviewed and published immediately upon acceptance

- cited in PubMed and archived on PubMed Central

- yours - you keep the copyright 